\title{
Attitude Towards Electronic-Prescription and Associated Factors Among Physicians at University of Gondar Referral Hospital: Institution Based Cross-Sectional Study
}

Libsuye Yalgaw Zimamu ( $\square$ libsuye@gmail.com )

DebreTabor Health Science College

Gashaw Mehiret Wubet

Debre Tabor University

\section{Research Article}

Keywords: Attitude, Ethiopia, Gondar, Physician, Prescription

Posted Date: December 22nd, 2021

DOI: https://doi.org/10.21203/rs.3.rs-1166816/v1

License: (c) (1) This work is licensed under a Creative Commons Attribution 4.0 International License.

Read Full License 
ATTITUDE TOWARDS ELECTRONIC-PRESCRIPTION AND ASSOCIATED FACTORS AMONG PHYSICIANS AT UNIVERSITY OF GONDAR REFERRAL HOSPITAL: INSTITUTION BASED CROSS-SECTIONAL STUDY

Libsuye Yalgaw Zimamu ${ }^{1}$ :libsuye@gmail.com,Gashaw Mehiret Wubet ${ }^{2}$ : mehiretg21stdr@gmail.com,

Short running title: Attitude towards electronic-prescription and associated factors among physicians

Authors affiliations:

${ }^{1}$ Department of Health Informatics, Debretabor Health Sciences College, Debre Tabor, Ethiopia

${ }^{2}$ School of Medicine, College of Medicine and Health Sciences, Debre Tabor University, Debre Tabor, Ethiopia.

Corresponding author: Libsuye Yalgaw Zimamu' ${ }^{1}$ libsuye@gmail.com

Department of Health Informatics, Debretabor Health Sciences College, Debre Tabor, Ethiopia

Email:libsuye@gmail.com 


\section{ABSTRACT}

Background: Electronic prescription is described by the United States Centers for Medicare and Medicaid Services as the broadcast utilizing electronic medium, of prescription or prescriptionrelated information between prescriber, distributor, pharmacy benefit manager, or health plan, either openly or through an agent, including an electronic prescribing system. the aim of this study was designed to assess attitudes towards electronic prescription and associated factors among physicians at the University of Gondar referral hospital 2021. Gondar, Ethiopia.

Methods: Hospital-based Cross-sectional study was used among $(\mathrm{n}=152)$ physicians who have involved with a response rate of $88.8 \%$. Data were collected using structured self-administered questionnaires from August 1 to September 1/2021. The collected data were entered into Epiinfo Version 7.2 and exported to SPSS version 23 software for analysis. Descriptive statistics using frequency and other summary statistics were using present socio-demographic and clinical characteristics of participants. Bivariate and multivariable logistic regression was employed to identify factors associated with dependent variables. Odds ratio (OR), with $95 \% \mathrm{CI}$ and $\mathrm{p}$ value $<$ 0.05 were computed to determine the level of significance.

Results: Based on the operational definition the overall score of attitudes to an electronic prescription of physicians from the University of Gondar referral hospital was 76.8\% [95\% CI: 66.7-84.2]. Among the applicant variables for multivariable analysis two variables like age of the respondents [AOR: 2.48 (95\% CL:1.055-5.830], and the monthly salary of the respondents [AOR: 8.29(95\%CL: 3.002-22.89] had to have a significant association with electronicprescription.

Conclusion and recommendation: The overall score of attitudes to the electronic prescription of physicians from the University of Gondar referral hospital was good. Age and a monthly salary of the respondents were significantly associated with an electronic prescription from the working organization university of Gondar referral hospital, and health care policymakers and hospital managers need to develop and institutionalize evidence-based widespread preparation of stakeholders especially prescribers and communications development earlier than its acceptance to build it doing well and victorious.

Keywords: Attitude, Ethiopia, Gondar, Physician, Prescription 


\section{INTRODUCTION}

\section{Background of the study}

For several years, the written prescription has been the technique excellent for physicians to communicate decisions on drug treatment, and pharmacists to dispense medicine, while at the same time being a source for the patient about how to use the medication to increase its benefit. currently, the medical prescription is at the transitional stage between paper and electronic state. When adopting an old-style process to the new electronic period, unique opportunities and challenges are offered to the involved performers like prescribers, patients, pharmacists, and also health care and EHR-system providers, and other stockholders(1). The traditional way of communication was by Prescription which is a written order by the doctor to the pharmacist. It has a status of a legal document. Re dispensing with repeated use of the same prescription is illegal.

Electronic prescribing is defined by the US Centers for Medicare and Medicaid Services (CMS) as the transmission using electronic media, of prescription or prescription-related information between prescriber, dispenser, pharmacy benefit manager, or health plan, either directly or through an intermediary, including an e-prescribing network(2).

Electronic prescribing is the advancement of a traditional technique to technological advancement. It is an integral component of the health information technology (HIT) system, an inter-operational platform, joining communication gaps among doctors, patients, nurses \& pharmacists. It has the potential to augment the safety of pharmacological treatment to reduce the morbidity associated with medication errors by reducing illegible handwriting, providing alerts by drug-drug interaction and drug allergy. The time spends handling the prescription renewal requests was considerably reduced. Electronic prescribing for controlled substances curbs the abuse and diversion of prescription drugs. This is by substantially reducing prescription fraud associated with paper prescriptions like falsifying prescriptions, prescription pad theft, and forgery. (3)

E-prescription is a tool for prescribers to electronically send an accurate, error-free, and understandable prescription directly to a pharmacy from the point of care. It allows the patient to improve safety through electronically checking patient allergies contraindication etc security and accuracy of his prescriptions, saving his time during handling prescription renewals by making it electronically with his pharmacy(4). 
Mistakes with e-prescribing are seen to be on the rise soon after its implementation. It could be attributed to technology factors like poor user interface design like auto-populate features and dropdown menus, end-user factors like poor knowledge of the e-prescribing platforms or unintentionally entering improper information, and environmental factors such as lack of time or poor location of the computer(3).

gap between physicians perceived value of e-prescribing and their intent adopt this practice.(8) Their reluctance to embrace the changeover from paper to computerized systems was based in large part on the perception that e-prescribing is time efficient.

E-prescribing system has the potential to greatly reduce adverse pharmaceutical effects driving from transcription, drug- drug interaction, allergies and dosage errors, to name a few indeed studies show significant improvements associated with e-prescribing implementation, including an $86 \%$ in decrease serious medication errors and increase in Medicare formulary adherence from $14 \%$ to $88 \%$.(8)Despite this evidence, however, providers have been slow to adopt e- prescribing technology due mainly to cost and regulatory constraints in the health industry.

Therefore, this study is designed to assess the perceptions of health care professionals towards e prescriptions, to identify possible barriers and to provide recommendation based on the results obtained. This may be helpful to know the current status of physician attitude and perceptions and to take action for the improvement. 


\section{METHODS AND MATERIALS}

\section{Study Setting}

The study was conducted in University of Gondar referral hospital, which is found in Gondar town, Amara region of North West Ethiopia far from Addis Ababa and Bahirdar $772 \mathrm{~km}$ and $168 \mathrm{~km}$ respectively. UoG comprehensive specialized hospital has 1049 health professionals and 653 beds were available. Patients are referred from primary health unit to this hospital that provides specialized healthcare services. UoG referral hospital currently offers a wide spectrum of services both preventive and curative as well as serving as a primary, district and tertiary hospital. Some of the services offered by the hospital are surgical, pharmaceutical, medicinal, social work, laboratory, dental, occupational therapy and intensive care services to mention but a few. It has a staff complement of 1915 distributed across different departments. There are about 450 nurses and 171 physicians including 67 GP.

\section{Study Design and Period}

An institutional based cross-sectional study was conducted to assess the Attitude of eprescription among physicians at UoG referral hospital. The study was conduct from August 1/2013 to September 1/2014 E/C.

\section{Source Population}

All Physicians working in University of Gondar referral Hospital were taken as source population.

\section{Study Population}

The study subjects were all physicians working in university of Gondar referral hospital for six (6) months and above during the study period.

\section{Inclusion and Exclusion Criteria.}

\section{Inclusion Criteria}

All physicians who are working at university of Gondar referral hospital were included in the study.

\section{Exclusion Criteria}

Study participants who are seriously ill and absent from work during the data collection period were excluded from this study.

\section{sample size determination}

The desired sample size is calculated using single population proportion formula. Formula: 


$$
n=\frac{(\mathrm{Z} \alpha / 2)^{2} p(1-p)}{d^{2}}
$$

However, because of the absence of previous similar studies in Ethiopia for p-values well as small number of study population we have, all physicians working in UOGCSH were participated in the study.

\section{Sampling technique and procedure}

The study participants were selected by using census method which is the method of statistical enumeration where all members of the study population are studied. Based on the above assumption for our study the participants were all physicians working in university of Gondar referral hospital.

So, study population=171, study participant also 171 .

\section{Study Variables}

\section{Dependent Variable}

Attitude towards e-prescription (positive or negative)

\section{Independent Variables}

○ Socio-demographic factors: Age, sex, experience, profession, monthly income

○ Behavioral factors: Attitude, by preparing question and ask who scores mean and above have good attitude, who scores less than the mean have poor attitude.

○ Technical factors: EPS training, past EPS experience, computer skill (literacy), computer at home

○ Organizational factors: Computer access at office, internet access at office, presence of IT department in the organization, availability of IT technical person.

\section{Operational Definition}

Attitude: is persistent disposition to act either positive or negative towards eprescription Score will categorized $<50 \%$ "negative", and $>=50 \%$ positive attitude(14).

$>$ Electronic prescription: defined as a technology applies on drug prescription either online or offline used to computer, tablet, and hand phone systems used to prescribing by physicians(15). 


\section{Data collection tools and techniques}

Quantitative data was collected using self-administered questionnaire, Socio-demographic, behavioral, technical and organizational variables was included in the questionnaire. Questionnaire was prepared in English this is because the study participants is well educated and they can easily understand English and if the questioner translated in to local language (Amharic) it was create some difficulty to understand.

\section{Data quality control}

Data collection were supervised for correct implementation of procedures by supervisors and the investigator. Completeness and consistency of the questionnaire was also be checked at the end of data collection.

\section{Data analysis and processing}

After the data collection, the response was code and enter in to computer by using EPI-info data version 7 statistical packages, and $10 \%$ of the response were randomly selected and checked for the consistency of the data entry. SPSS version 20 also was used for data analysis. Frequency and Percentage were calculated to all variables which are related to objective of the study, and Bivariate and multivariable logistic regression was employed to identify factors associated with dependent variables. Odds ratio (OR), with $95 \% \mathrm{CI}$ and $\mathrm{p}$ value $<0.05$ were computed to determine the level of significance.

\section{Data Dissemination Plan}

A copy of the report will be given to UoG referral hospital, CHMS Department of Health informatics and other concerned bodies. It is also expected that the result of this study will be disseminated to the public through media. Additionally, the result may be presented on scientific conferences and published in scientific journals.

\section{Ethical Consideration}

Ethical clearance was obtained from institutional review board (IRB) of the University of Gondar. A written letter of permission from the research coordination committee were submitted to UGCSH Administration to grant permission for conducting the study. The study participants were provided with clear information about the purpose of the study and asked if they are willing to participate in the study. Data was collected after receiving verbal consent from those who are willing to participate in the study. Anonymity of the respondents was preserved and their information were kept secret and were not be disclosed to anyone except for the purpose of the study. 


\section{RESULT}

\section{Socio demographic characteristics of respondents}

Out of 171 study participants, 152(88.8\%) were involved in this study and it produces a response rate of $88.8 \%$. The mean age of the study participants was $34.5( \pm \mathrm{SD})$ years which ranges from (23-56).

The majority of respondents, 95(62.5\%) were male, and more than half of the respondents, 75 (49.3\%) were aged between (20-35), and nearly half of the respondents, 65 (42.8\%) had degree holders. Regarding the profession, 59(38.8\%) were General practitioners (GP), and the mean monthly salary of the respondents was 12,214.43(305.36\$) Ethiopian birr. Concerning work experience $71(46.7 \%$ were working 1-5years at the University of Gondar referral hospital

\section{(Table1).}

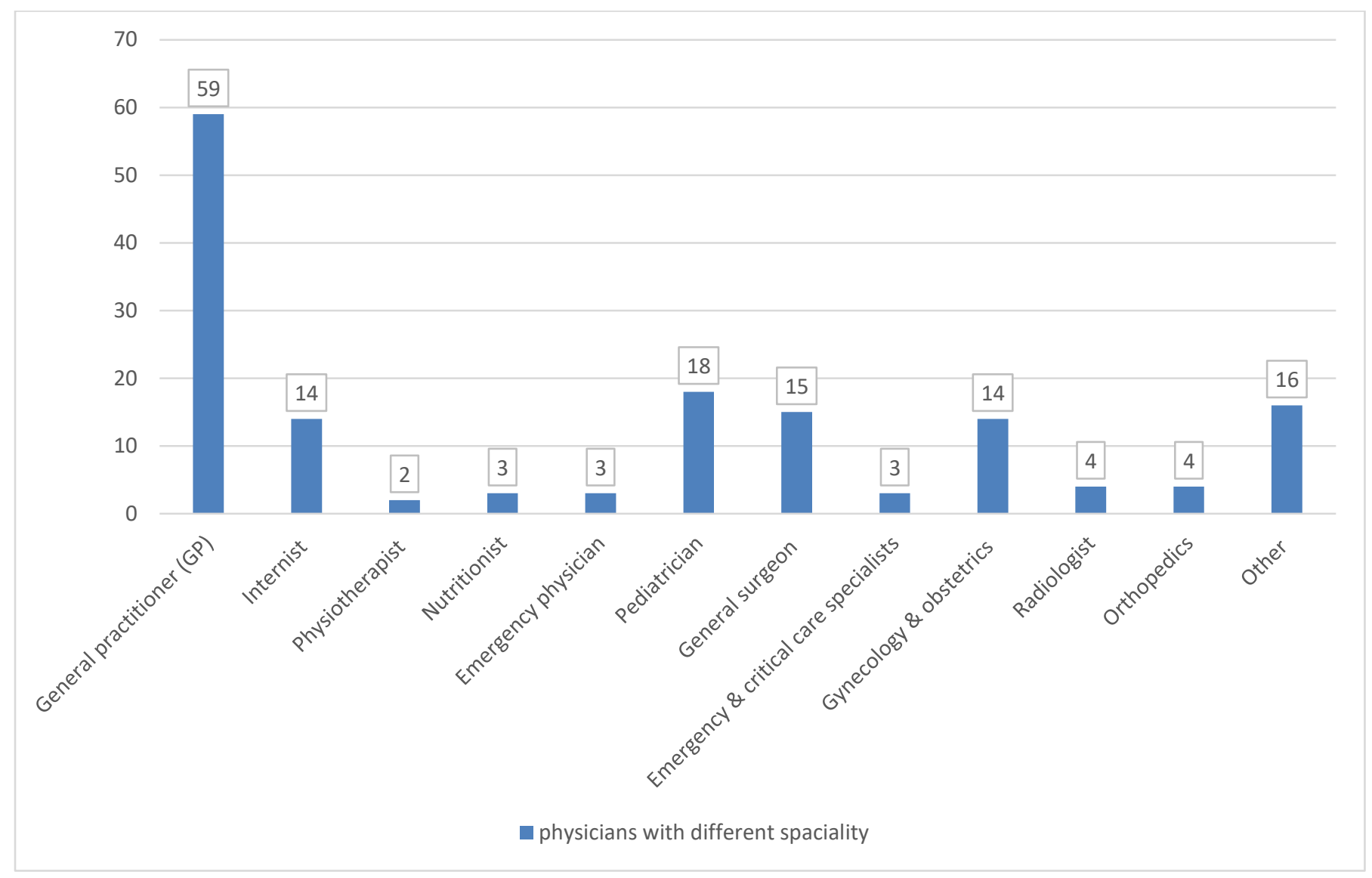

Figure 1:Number of physicians with different spatiality in universityof Gondar referral hospital Gondar,Ethiopia,2021 
Table 1: socio-demographic characteristics of physicians working in university of Gondar referral hospital Gondar, Ethiopia, 2021, $(n=152)$

\begin{tabular}{|c|c|c|c|}
\hline Variable & Category & $(n=152)$ & $\%$ \\
\hline \multirow[t]{3}{*}{ Age } & $20-35$ & 83 & $54.6 \%$ \\
\hline & $36-45$ & 57 & $37.5 \%$ \\
\hline & $45+$ & 12 & $7.9 \%$ \\
\hline \multirow[t]{2}{*}{ Sex } & Male & 95 & $62.5 \%$ \\
\hline & Female & 57 & $37.5 \%$ \\
\hline \multirow[t]{2}{*}{ Education status } & Degree & 65 & $42.8 \%$ \\
\hline & MSc and above & 87 & $57.2 \%$ \\
\hline \multirow[t]{12}{*}{ Profession } & General practitioner (GP) & 59 & $38.8 \%$ \\
\hline & Internist & 13 & $9.2 \%$ \\
\hline & Physiotherapist & 2 & $1.3 \%$ \\
\hline & Nutritionist & 3 & $1.97 \%$ \\
\hline & Emergency physician & 3 & $1.97 \%$ \\
\hline & Pediatrician & 18 & $11.8 \%$ \\
\hline & General surgeon & 15 & $9.86 \%$ \\
\hline & Emergency \& critical care specialists & 2 & $1.97 \%$ \\
\hline & Gynecology \& obstetrics & 14 & $9.2 \%$ \\
\hline & Radiologist & 4 & $2.63 \%$ \\
\hline & Orthopedics & 4 & $2.63 \%$ \\
\hline & Other & 16 & $10.5 \%$ \\
\hline \multirow[t]{3}{*}{ Working Experience } & $<5$ & 80 & $52.6 \%$ \\
\hline & $6-10$ & 51 & $33.6 \%$ \\
\hline & $10+$ & 21 & $13.8 \%$ \\
\hline \multirow[t]{3}{*}{ Work practicing at this hospital } & $<1$ year & 18 & $11.9 \%$ \\
\hline & $1-5$ year & 71 & $46.7 \%$ \\
\hline & $5+$ year & 63 & $41.4 \%$ \\
\hline \multirow[t]{3}{*}{ Monthly salary } & $<9056$ & 41 & $27 \%$ \\
\hline & $9056-11305$ & 43 & $28.3 \%$ \\
\hline & $11305+$ & 68 & $44.7 \%$ \\
\hline
\end{tabular}




\section{Attitudes of Physicians towards e-prescription}

Based on the operational definition the overall score of attitudes to e-prescription of physicians from the University of Gondar referral hospital was 76.8\% [95\% CI: 66.7-84.2]. The findings of physicians to e-prescription were consistent with the operational definition. The findings of eprescription of physicians showed that physicians expressed a high level of satisfaction with improving quality of care and reducing error 150 (98.6\%), Improve the quality of work-life 150(98.6\%), give benefitsoutweighthecost152(100\%). On the other hand, Administrative rigidity is a possiblebarrier38 (25\%), Notfeasible82(53.9\%), Improve patient's satisfaction20 (13.2 \%) were reported as unsatisfied (Table2).

Table 2:- Level of attitudes of physicians towards e-prescription by different dimensions among physicians in university Gondar referral hospital Gondar, Ethiopia, 2021 (n=152).

\begin{tabular}{|c|c|c|c|}
\hline Variable & Category & $(n=152)$ & $\%$ \\
\hline & Satisfied & 150 & $98.6 \%$ \\
\hline Improve quality of care and reduce error & Dissatisfied & 2 & $1.3 \%$ \\
\hline \multirow[t]{2}{*}{ Improve quality of work life } & Satisfied & 150 & $98.6 \%$ \\
\hline & Dissatisfied & 2 & $1.3 \%$ \\
\hline \multirow[t]{2}{*}{ Improve patients' satisfaction } & Satisfied & 132 & $86.8 \%$ \\
\hline & Dissatisfied & 20 & $13.2 \%$ \\
\hline \multirow[t]{2}{*}{ The benefits outweigh the cost } & Satisfied & 152 & $100 \%$ \\
\hline & Dissatisfied & 0 & $0 \%$ \\
\hline \multirow[t]{2}{*}{ Decrease burden on physicians } & Satisfied & 149 & $98 \%$ \\
\hline & Dissatisfied & 3 & $1.97 \%$ \\
\hline \multirow[t]{2}{*}{ Feasible of electronic system } & Satisfied & 70 & $46.05 \%$ \\
\hline & Dissatisfied & 82 & $53.9 \%$ \\
\hline \multirow[t]{2}{*}{ Administrative rigidity is possible barrier } & Satisfied & 114 & $75 \%$ \\
\hline & Dissatisfied & 38 & $25 \%$ \\
\hline \multirow{2}{*}{$\begin{array}{l}\text { Cannot be used without the availability of } \\
\text { skilled resources and support }\end{array}$} & Satisfied & 146 & $96.05 \%$ \\
\hline & Dissatisfied & 6 & $3.9 \%$ \\
\hline \multirow[t]{2}{*}{ Proper training would be required } & Satisfied & 149 & $98 \%$ \\
\hline & Dissatisfied & 3 & $1.97 \%$ \\
\hline
\end{tabular}




\begin{tabular}{lllc}
\hline I would devote time to training for its & Satisfied & 150 & $98.6 \%$ \\
\cline { 2 - 4 } implementation & Dissatisfied & 2 & $1.3 \%$ \\
\hline An e prescribing system should be & Satisfied & 143 & $94.04 \%$ \\
\cline { 2 - 4 } implemented in UOGCSH hospital & Dissatisfied & 9 & $5.92 \%$ \\
\hline
\end{tabular}

\section{Organizational and technical characteristics of respondents}

The majority of respondents 111(73.02\%) were had their personal computer, half of the respondents 67 (44.07\%) of them reported that they have a computer at their office, 35 (23.02\%) respondents had internet at the office,36(23.6\%) respond that have a computer at home, $8(5.2 \%)$ were a response that organization has to stand by generator, $117(76.9 \%)$ were reported organization has active or functional IT department, and 90(59.2\%) were Organization have IT, technical person, on the other hand, $152(100 \%)$ of respondents were not taking training on eprescription and working with e-prescribing ever before, and the study subjects were used computer for data recording, report generating, reading, and video accessing are 142(93.4\%),147(96.7\%),69(45.4\%), and 118(77.6\%)respectively(Table 3).

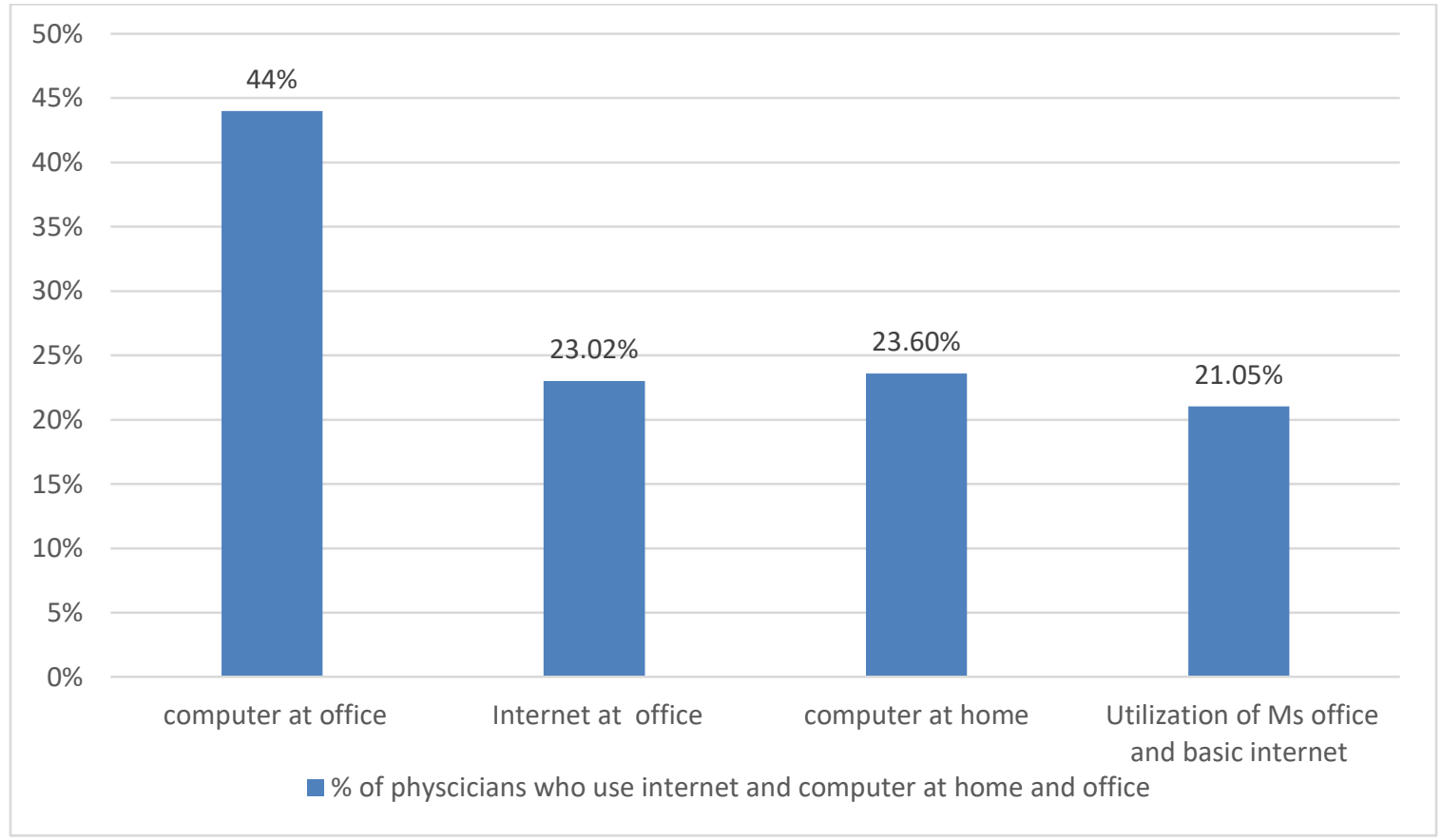

Figure 2:Number of physicians having computer and internet service at their home and office university of Gondar referral hospital, Gondar, Ethiopia,2021 
Table 3:Organizational and technical characteristics of respondents at university of Gondar referral hospital Gondar, Ethiopia,2021(n=152).

\begin{tabular}{|c|c|c|c|}
\hline Variable & Category & $(n=152)$ & $\%$ \\
\hline \multirow[t]{2}{*}{ Computer at your office } & Yes & 67 & $44.07 \%$ \\
\hline & No & 85 & $55.9 \%$ \\
\hline \multirow[t]{3}{*}{ How use it } & I have my own computer & 111 & $73.02 \%$ \\
\hline & $\begin{array}{l}\text { I shared one computer with one } \\
\text { other staff }\end{array}$ & 37 & $24.34 \%$ \\
\hline & $\begin{array}{l}\text { I shared one computer with two } \\
\text { other staff }\end{array}$ & 4 & $2.6 \%$ \\
\hline \multirow[t]{2}{*}{ Internet at your office } & Yes & 35 & $23.02 \%$ \\
\hline & No & 117 & $76.9 \%$ \\
\hline \multirow{3}{*}{$\begin{array}{l}\text { Organization has active or functional } \\
\text { IT department }\end{array}$} & Yes & 117 & $76.9 \%$ \\
\hline & No & 1 & $0.65 \%$ \\
\hline & I don't know & 34 & $22.3 \%$ \\
\hline \multirow[t]{3}{*}{ Organization have IT technical person } & Yes & 90 & $59.2 \%$ \\
\hline & No & 8 & $5.26 \%$ \\
\hline & I don't know & 54 & $35.5 \%$ \\
\hline \multirow[t]{3}{*}{ Organization have stand by generator } & Yes & 8 & $5.2 \%$ \\
\hline & No & 98 & $64.4 \%$ \\
\hline & I don't know & 46 & $30.26 \%$ \\
\hline \multirow[t]{2}{*}{ Computer at home } & Yes & 36 & $23.6 \%$ \\
\hline & No & 116 & $76.3 \%$ \\
\hline \multirow{2}{*}{$\begin{array}{l}\text { Computer literate performing office } \\
\text { and basic internet }\end{array}$} & Yes & 32 & $21.05 \%$ \\
\hline & No & 120 & $78.9 \%$ \\
\hline \multirow{2}{*}{$\begin{array}{l}\text { Working with e-prescribing ever } \\
\text { before }\end{array}$} & Yes & 0 & $0.00 \%$ \\
\hline & No & 152 & $100 \%$ \\
\hline \multirow[t]{3}{*}{ e-prescription training before } & Yes & 0 & $0.00 \%$ \\
\hline & No & 152 & $100 \%$ \\
\hline & I don't know & 1 & $0.65 \%$ \\
\hline Data recording & Yes & 142 & $93.4 \%$ \\
\hline
\end{tabular}




\begin{tabular}{|c|c|c|c|}
\hline & No & 10 & $6.5 \%$ \\
\hline \multirow[t]{2}{*}{ Report generating } & Yes & 147 & $96.7 \%$ \\
\hline & No & 5 & $3.28 \%$ \\
\hline \multirow[t]{2}{*}{ Reading } & Yes & 69 & $45.4 \%$ \\
\hline & No & 83 & $54.6 \%$ \\
\hline \multirow[t]{2}{*}{ Video accessing } & Yes & 118 & $77.6 \%$ \\
\hline & No & 34 & $22.36 \%$ \\
\hline \multirow[t]{2}{*}{ Other's purpose } & Yes & 137 & $90.13 \%$ \\
\hline & No & 15 & $9.86 \%$ \\
\hline
\end{tabular}

\section{Factors associated with e-prescription}

Findings based on the analytical part, which results variables such as sex of the respondents [OR:2.696(1.194-6.091)], age of the respondents [OR:0.421(0.073-2.437], profession of the respondents[OR:3.7(.561-24.42], educational status of the respondents [OR:1.878(.0.8744.033],monthly salary [OR: 7.0(2.66-18.45],working experience of the respondents[OR:1.82(.845-3.918], working practice at this hospital of the respondents[OR:.245(.029-2.060], Decrease burden on physicians [OR:.447(.783-3.513]were having a p-value less than 0.2 , but variables such as sex, the profession of the respondents, educational status of the respondents, work experience of the respondents, working practice at this hospital, and decrease burden on physicians were disappeared from the final stage of multivariable analysis. Regarding multivariable logistic analysis two variables like age of the respondents who have age <35year old 2.48 times more likely practicing e-prescription than age >35years old [AOR: 2.48 (95\%CI:1.055-5.830 p:value=0.003], and a monthly salary of the respondents who have monthly salary<9056.00 birrs 8.29 times more likely practicing electronic prescription than salary $>9056.00$ birrs [AOR: $8.29(3.002-22.89$ p:value $=0.001$ ] had to have a significant association with e-prescription. (Table 4).

Table 4:Factors associated with e-Prescription among physicians in university of Gondar referral hospital. Gondar, Ethiopia, 2021 (n=152). 


\begin{tabular}{|c|c|c|c|c|}
\hline \multirow[t]{2}{*}{ Variables } & \multicolumn{2}{|c|}{ Attitude towards e-prescription } & \multirow[t]{2}{*}{$\operatorname{COR}(95 \% \mathrm{CI})$} & \multirow[t]{2}{*}{$\operatorname{AOR}(95 \%, \mathrm{CI})$} \\
\hline & Yes & No & & \\
\hline $\begin{array}{l}\text { Sex } \\
\text { Male } \\
\text { Female }\end{array}$ & $\begin{array}{l}43(28.2 \%) \\
51(41.8 \%)\end{array}$ & $\begin{array}{l}36(23.6 \%) \\
22(18 \%)\end{array}$ & $\begin{array}{l}\text { [OR:2.696(1.1946.091)] } \\
1\end{array}$ & ------------------ \\
\hline $\begin{array}{l}\text { Age } \\
<35 \\
36-45 \\
>45\end{array}$ & $\begin{array}{l}32(26.23 \%) \\
47(38.5 \%) \\
25(16.4 \%)\end{array}$ & $\begin{array}{l}25(20.5 \%) \\
18(14.8 \%) \\
5(3.2 \%)\end{array}$ & $\begin{array}{l}\text { [OR:0.49(0.231-1.042] } \\
1\end{array}$ & $\begin{array}{l}*[\text { AOR:0.40349(.172.948] } \\
1\end{array}$ \\
\hline $\begin{array}{l}\text { Monthly salary } \\
<9056 \\
9056-11305 \\
>11305\end{array}$ & $\begin{array}{l}17(11.2 \%) \\
40(32.9 \%) \\
37(30.33 \%)\end{array}$ & $\begin{array}{l}18(11.8 \%) \\
25(20.5 \%) \\
15(12.3 \%)\end{array}$ & 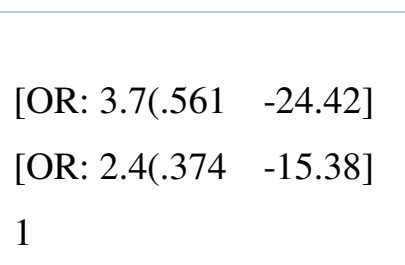 & *[AOR: 8.29(3.002-22.89] \\
\hline $\begin{array}{l}\text { Feasibility } \\
\text { Satisfied } \\
\text { Dissatisfied }\end{array}$ & $\begin{array}{l}55(36.2 \%) \\
39(31.97 \%)\end{array}$ & $\begin{array}{l}43(28.3 \%) \\
15(12.3 \%)\end{array}$ & $\begin{array}{l}\text { [OR:1.82(.845-3.918] } \\
1\end{array}$ & ---------------- \\
\hline $\begin{array}{l}\text { Improve } \\
\text { patients' } \\
\text { satisfaction } \\
\text { Satisfied } \\
\text { Dissatisfied }\end{array}$ & $\begin{array}{l}72(59 \%) \\
22(14.5 \%)\end{array}$ & $\begin{array}{l}42(34.43 \%) \\
16(10.5 \%)\end{array}$ & $\begin{array}{l}\text { [OR: .245(.029-2.060] } \\
1\end{array}$ & ------------------- \\
\hline $\begin{array}{l}\text { Decrease burden } \\
\text { on physicians } \\
\text { Satisfied } \\
\text { Dissatisfied }\end{array}$ & $\begin{array}{l}56(36.8 \%) \\
38(31.14 \%)\end{array}$ & $\begin{array}{l}44(28.9 \%) \\
14(14.48 \%)\end{array}$ & $\begin{array}{l}\text { [OR:.447(.783-3.513] } \\
1\end{array}$ & ------------------ \\
\hline $\begin{array}{l}\text { Proper training } \\
\text { would be required } \\
\text { Satisfied } \\
\text { Dissatisfied }\end{array}$ & $\begin{array}{l}36(29.5 \%) \\
43(35.25 \%)\end{array}$ & $\begin{array}{l}25(20.49 \%) \\
18(14.75 \%)\end{array}$ & $\begin{array}{l}\text { [OR: } 1.659(.206-.972] \\
1\end{array}$ & ----------------- \\
\hline
\end{tabular}




\section{DISCUSSION}

The current study tried to assess the magnitude of e-prescription among physicians and the overall score attitudes of physicians on e-prescription from the organization in the study area was 76.8\% [95\% CI: 66.7-84.2]. Also attitudes of physicians on e-prescription majority of professionals had high level of satisfaction with Improve quality of care and reduce error 150 (98.6\%), Improve quality of work life 150(98.6\%), give benefits outweigh the cost 152(100\%). On the other hand, administrative rigidity is possible barrier 38 (25\%), Not feasible 82(53.9\%), Improve patients' satisfaction $20(13.2 \%)$ were reported as unsatisfied

The total magnitude of physicians for attitudes of e-prescription from their organization was 76.8\% [95\% CI: 66.7-84.2]. concurrent and similar study conducted in Sweden shows we demonstrated a relationship between the country of residence of physicians and their attitude towards e-prescribing for all the responses of Swedish physicians $82 \%$ regarded e-prescribing as time saving, $88.1 \%$ as being safer and $96 \%$ as providing a batter service for patients.(16)

The current study conducted out of 171 study participants, Majority of respondents, 95(62.5\%) were male and more than half of the respondents, 75 (49.3\%) were those age between (20-35), with response rate of $88.8 \%$ were A cross sectional study conducted at Kottayam, Kerala, INDIA. Of Kerala has started the e-health initiative shows Two hundred and fifty seven prescribing doctors of age range 22-60 years participated of which $49 \%$ were females and $51 \%$ males with Response rate was $73 \%$ (257/350) (10). the current study is lower than study conducted at chain to assess attididues of physicians on e-prescription Hundred physicians were approached with the help of the consultancy, out of which 90 physician responded the result shows that majority of the physicians $(86 \%)$ had positive attitude towards e-prescription the experience of the physician and E-prescribing facility helps to spend lesser time on prescribing the drugs when compared to hand written prescribing $(\mathrm{P}<0.05)(10)$. The two studies showed that to assess the attitudes of physicians on e-prescription of physicians among chain found to be this may be in the current study area absence of different initiatives to exercise e-health technologies, lack of motives ,bad working environment.

From the current study Majority of respondents $111(73.02 \%)$ were having their own personal computer, half of respondents $67(44.07 \%)$ of them reported that they have computer at their office, $35(23.02 \%)$ respondents were have internet at office ,36(23.6\%) respond that have computer at home, $8(5.2 \%)$ were response that organization have stand by generator, 
117(76.9\%)were reported organization have active or functional IT department, and 90(59.2\%) were Organization have IT technical person, on the other hand $152(100 \%)$ of respondents were not taking training on e-prescription and working with e-prescribing ever before, and the study subjects were used computer for the purpose of data recording, report generating, reading, and video accessing are 142(93.4\%),147(96.7\%),69(45.4\%), and 118(77.6\%)respectively.

The study analyzed e-prescription from the physicians' view in the public sector at University of Oulu user experience, acceptance of technology, success in implementing and using information system with the help of five themes forming a framework (information quality, service quality, system quality, perceived ease-of-use, perceived usefulness and intention to use) (12).

A survey was conducted in four hospitals in Nigeria to determine the economic, technical and organizational feasibility of adopting e-prescribing included 42 medical practitioners - doctors, pharmacists, pharmacy technicians and assistants - working at the hospitals at the time of the survey so, respondents felt that implementation of an EP system is economically feasible $(\mathrm{p}=0.031)$ and organizationally feasible $(\mathrm{p}=0.032) .(13)$

The current study revealed that higher numbers of physicians were dissatisfied than the above study. The possibility of dissatisfaction would be due to lack of computer at their office and home, absence of internet accesses at office as well as at their home, lack of training related to eprescription those who perform better.

Factors like monthly salary of the respondents were significantly associated 8.29 times with physicians to adapt e-prescription. The findings of the current study are inversely related with above study that in Nigeria to determine the economic, technical and organizational feasibility of adopting e-prescribing so, respondents felt that implementation of an EP system is economically feasible $(p=0.031)$ and organizationally feasible $(p=0.032) .(13)$ The possible difference may be due to inadequate funding by the government does not provide for the health sector to acquire the necessary resources and training to enhance the skills of physicians in health care industry.

Generally, the magnitude of attitudes of physicians on e-prescription from the current study is higher and influenced with factor like monthly salary, and age of respondents. 


\section{Limitation of the study}

The current study has some limitations such as related kinds of literature and as data were collected based on self-reported information, the possibility of recording errors and recall biases.

\section{Conclusion}

the overall score attitudes of physicians on e-prescription from the organization in the study area was good in the university of Gondar referral hospital. variables for multivariable analysis variables like age and the monthly salary of the respondents had to have a significant association with e-prescription. monthly salary of the respondents was significantly associated with eprescription of monthly salary less than 9,056.00 of the respondents from the University of Gondar referral hospital compared with those who had monthly salary more than 11,305.00 with attitudes ready to adapt e-prescription of the respondents from the working organization.

\subsection{Recommendations}

Recommendations were given for the responsible bodies based on the findings of the research and conclusions. The followings are the appropriate recommendations for different responsible bodies.

\section{To Hospital Administrators}

Recommendations were given for the responsible bodies based on the findings of the research and conclusions.

\section{To Researchers}

$>$ Since there was no adequate research done in Ethiopia on this topic the findings of the research are expected to be used by another researcher who wants to conduct similar research. 


\section{REFERENCES}

1. Lina Hellström*1, 3, Karolina Waern1,3, Emelie Montelius1, Bengt Åstrand2,3, , Tony Rydberg1 aGP. Physicians' attitudes towards ePrescribing - evaluation of a Swedish full-scale implementation. 2009.

2. Lanham AE, Cochran GL, Klepser DG. Electronic prescriptions: opportunities and challenges for the patient and pharmacist. 2016.

3. Palappallil1 DS, * CP. Perceptions of Prescribers towards Electronic Prescription: A Pre-Implementation Evaluation. 2018.

4. Betalo ML. THEORETICAL APPROACH TO ELECTRONIC PRESCRIPTION SYSTEM IN WOLAITA SODO UNIVERSITY REFERRAL HOSPITAL. 2018.

5. T Steinschaden GPaBAs. Physicians' attitudes towards eprescribing: a comparative web survey in Austria and Sweden. 2009.

6. Ahmed I Albarrak * EAAR, Rwaa Kamil Fatani,, Shoog Ibrahim Al Ageel RM. Assessment of legibility and completeness of handwritten and electronic prescriptions. 2014.

7. Poojitha1 M, Bhoomadevi2 DA. Assessing the Attitude of the Physicians towards e-prescribing in Chennai. 2021.

8. Omotosho A. A survey of E-Prescription readiness in selected Nigeria Hospitals. 2015.

9. Ayatollahi H SF, Langarizadeh M. Clinicians' Knowledge and Perception of Telemedicine Technology.Perspectives in Health Information Management. 2015.

10. Poojitha M, Bhoomadevi A. Assessing the Attitude of the Physicians towards e-prescribing in Chennai. REVISTA GEINTEC-GESTAO INOVACAO E TECNOLOGIAS. 2021;11(4):4489-97.

11. Sebetci Ö, Çetin M. Developing, applying and measuring an e-Prescription Information Systems Success Model from the persperctives of physicians and pharmacists. Health Policy and Technology. 2016;5(1):84-93.

12. Track N. E-PRESCRIPTION FROM THE PHYSICIANS'VIEW IN THE PUBLIC SECTOR.

13. Omotosho A, Emuoyibofarhe J, Ayegba P, Meinel C. E-Prescription in Nigeria: A Survey. Journal of Global Pharma Technology. 2018.

14. Aldughayfiq B, Sampalli S. Digital Health in Physicians' and Pharmacists' Office: A Comparative Study of e-Prescription Systems' Architecture and Digital Security in Eight Countries. OMICS: A Journal of Integrative Biology. 2021;25(2):102-22.

15. Hellström L, Waern K, Montelius E, Åstrand B, Rydberg T, Petersson G. Physicians' attitudes towards ePrescribing-evaluation of a Swedish full-scale implementation. BMC medical informatics and decision making. 2009;9(1):1-10.

16. Jariwala KS, Holmes ER, Banahan III BF, McCaffrey III DJ. Adoption of and experience with eprescribing by primary care physicians. Research in Social and Administrative Pharmacy. 2013;9(1):1208. 